\title{
Low-Affinity Neurotrophin Receptor p75 Promotes the Transduction of Targeted Lentiviral Vectors to Cholinergic Neurons of Rat Basal Forebrain
}

\author{
Inga Antyborzec $^{1}$ • Valerie B. O'Leary ${ }^{1,2} \cdot$ James O. Dolly $^{1} \cdot$ Saak V. Ovsepian ${ }^{1,3,4}$
}

Published online: 24 May 2016

(C) The American Society for Experimental NeuroTherapeutics, Inc. 2016

\begin{abstract}
Basal forebrain cholinergic neurons (BFCNs) are one of the most affected neuronal types in Alzheimer's disease (AD), with their extensive loss documented at late stages of the pathology. While discriminatory provision of neuroprotective agents and trophic factors to these cells is thought to be of substantial therapeutic potential, the intricate topography and structure of the forebrain cholinergic system imposes a major challenge. To overcome this, we took advantage of the physiological enrichment of BFCNs with a low-affinity $\mathrm{p} 75$ neurotrophin receptor $\left(\mathrm{p} 75^{\mathrm{NTR}}\right)$ for their targeting by lentiviral vectors within the intact brain of adult rat. Herein, a method is described that affords selective and effective transduction of BFCNs with a green fluorescence protein (GFP) reporter, which combines streptavidinbiotin technology with anti-p $75^{\text {NTR }}$ antibody-coated lentiviral vectors. Specific GFP expression in cholinergic neurons was attained in the medial septum and nuclei of the diagonal band Broca after a single intraventricular administration of such targeted vectors. Bioelectrical activity of
\end{abstract}

Electronic supplementary material The online version of this article (doi:10.1007/s13311-016-0445-3) contains supplementary material, which is available to authorized users.

Saak V. Ovsepian

saak.ovsepian@gmail.com

1 International Centre for Neurotherapeutics, Dublin City University, Dublin, Ireland

2 Institute of Radiation Biology, Helmholtz Zentrum Munich, German Research Center for Environmental Health, Neuherberg, Germany

3 Institute for Biological and Medical Imaging, Helmholtz Zentrum Munich, German Research Center for Environmental Health, Neuherberg, Germany

4 Munich School of Bioengineering, Technical University Munich, Munich, Germany
GFP-labeled neurons was proven to be unchanged. Thus, proof of principle is obtained for the utility of the lowaffinity $\mathrm{p} 75^{\mathrm{NTR}}$ for targeted transduction of vectors to BFCNs in vivo.

Key Words Alzheimer's disease · Basal forebrain cholinergic neurons $\cdot$ p75 neurotrophin receptor · Gene therapy ·

Streptavidin-biotin $\cdot$ Neuroprotection

\section{Introduction}

Delivery of therapeutics to selected cell groups or tissues is arguably one of the most promising and potentially highly beneficial areas of pharmaceutical research and theranostics. The notion of "magic bullets" eradicating diseases or enhancing specific functions of selected cellular groups proposed at the turn of the twentieth century by Paul Ehrlich has only recently been implemented with moderate success in medical research, yielding first beneficial results in experimental animals and preclinical trials $[1,2]$. The ultimate goal of targeting drugs or vectors is to provide a broader therapeutic window via concentration of goods in desired cells or tissues, and to minimize their off-site effects.

The differential vulnerability of various neuronal subpopulations to neurodegenerative disease provides the mechanistic grounds for the vast neurotherapeutic potential of gene targeting to different neurons. In particular, targeted provision of long-term trophic support to certain types of neurons or selective enhancement of the functionality of synapses assaulted by diseases such as Alzheimer's (AD), Parkinson's, Huntington's, and Lou Gehring's (also known as amyotrophic lateral sclerosis) can offer prospects of countering the progression of the 
neurodegenerative process with amelioration of neuronal and synaptic functions [3-5]. In $\mathrm{AD}$, for instance, loss of basal forebrain cholinergic neurons (BFCNs) is thought to contribute towards impairment of cortical and hippocampal functions and synaptic plasticity, leading to severe memory deficit with decline in cognition [6-9]. Both, behavioral and cognitive improvements in murine models and enhanced viability of cholinergic neurons in aged monkeys grafted with nerve growth factor (NGF)-secreting cells supports the beneficial potential of supplying protective or trophic agents to BFCNs [10-13], while the encouraging outcome from trials with implants of NGF-expressing autologous fibroblasts into the forebrain of patients with $\mathrm{AD}$ proves the clinical significance of neurotrophic therapy $[5,14,15]$. However, targeted provision of potential therapeutics to BFCNs turned out to be highly challenging, owing primarily to the intricate anatomy of the basal forebrain cholinergic system and wealth of neuronal types residing within the basal forebrain (BF) region. Attempts have been made at NGF delivery to BFCNs by adeno-associated virus or lentivirus capable of sustaining gene expression for prolonged periods [16, 17], with prevention of the loss of cholinergic neurons in vivo $[16,18]$. NGF delivery by a lentiviral approach using tetracycline-regulated promoters is claimed to enable control over neuronal loss and protein production within the brain [19]. The creation of CERE-110, an adeno-associated virus 2 vector system for dosedependent delivery of NGF to BFCNs, has been reported [20]. Nevertheless, without a targeted and effective delivery of neurotherapeutic candidates and vectors to BFCNs, efforts at meddling with their biology and functions are likely to prompt unfavorable side effects.

BFCNs are the only neuronal type in the forebrain enriched with the low-affinity neurotrophin receptor $\mathrm{p} 75$ $\left(\mathrm{p} 75^{\mathrm{NTR}}\right)$ throughout development and especially in adulthood [21, 22]. While the functional significance of the latter has remained unclear over the years, this unique BFCN characteristic has been successfully exploited for their targeted lesion with toxins and in vivo prelabeling with fluorescence markers for behavioral and electrophysiological experiments [23-30]. To the best of our knowledge, the utility of the $\mathrm{p} 75^{\mathrm{NTR}}$ for targeting and delivery of drug candidates or vectors to BFCNs has remained unexplored. We hypothesized that the $\mathrm{p} 75^{\mathrm{NTR}}$ could be used to facilitate the transfer of vectors to BFCNs in adult rat brains in vivo, and describe here an effective and novel method that affords targeted green fluorescence protein (GFP) transduction and stable expression in these cells, without compromising their electrophysiological characteristics. The outstanding challenges and potential future applicability of the described herein targeting strategy for basic and translational neurobiology are discussed.

\section{Materials and Methods}

\section{Experimental Animals}

All procedures involving rats conformed to the guidelines approved by the research ethics committee of Dublin City University (DCU) and the Department of Health and Children, Republic of Ireland. Rats of mixed sex $(n=3-5$ per in vivo experimental group; 43 animals in total), 1 to 3 months of age, were analyzed, except those used for the tissue culture experiments, which were younger ( $n=15$; see below). They were housed and bred in the animal housing facility of DCU $\left(21 \pm 1^{\circ} \mathrm{C}\right.$, humidity $36 \pm 2 \%$ in a $12 \mathrm{~h}$ light $/ 12 \mathrm{~h}$ dark cycle), with food and water provided ad libitum.

\section{Preparation of Viral Vectors}

Commercially available lyophilized mammalian expression plasmid stocks were purchased from a repository (https:// www.addgene.org). These included the following for second-generation lentiviral construction: 1) pMD2.G (5.8 $\mathrm{Kb}$, cat. \# 12259) encoding the vesicular stomatitis viral envelope glycoprotein; 2) pWPT-GFP $(9.47 \mathrm{~Kb}$, cat. \# 12255) for constitutive transgene expression - this vector provided the GFP gene for subcloning into pWPI (11 Kb, cat. \# 12254); 3) pCMV-d R8.2 (13.45 Kb, cat. \# 8455) used for lentiviral packaging [31]. These plasmids were bacterially amplified followed by purification through a QIA filter plasmid midi kit (cat. \# 12243; Qiagen, Hilden, Germany) with concentration and purity determination via A260/280 nm ratio assessment. Verification of the correct plasmid size was achieved using gel electrophoretic separation through $2 \%$ Tris-borate-ethylenediaminetetraacetic acid agarose of restriction-digested linearized plasmids (BamH1: pWPT-GFP; Pst1: pMD2.G; EcoR1/XhoR1: pCMV-d R8. 2; New England BioLabs, Ipswich, MA, USA) with insert sequence confirmation by double-stranded automated sequencing (Eurofins, Luxembourg). Stable transfection of HEK293FT cells and viral collection from supernatants were conducted under level II safety containment. Twenty-four hours prior to transfection, HEK293FT cells were seeded at 1 to $3 \times 10^{6}$ cells $/ 10 \mathrm{~cm}$ Petri dish in RPMI-Glutamax medium (61870036; Life Techologies, Carlsbad, CA, USA) with $10 \%$ fetal bovine serum. All solutions were sterilized by filtration through $0.22-\mu \mathrm{m}$ filters. The lentiviral transfer plasmid pWPI-GFP (encoding transduction reporter transgene), together with pCMV-d R8.2 (packaging) and pMD2. G (glycoprotein envelope) plasmid DNA were combined at a ratio of $4: 3: 1$. The precipitate was formed by adding $100 \mu \mathrm{g}$ DNA to $1 \times$ phosphate-buffered saline (PBS; 2 ml) and polyethylenimine [200 $\mu \mathrm{l}$; cat \# 23966 (Polyscience, Niles, IL, USA)]. The solution was briefly vortexed and incubated at room temperature (RT) for 30 
min. Following this, the solution was mixed again by gentle vortexing, and then added dropwise to the cells grown to $80 \%$ confluence. Flasks were rocked gently in a circular motion to distribute the precipitates, and incubated for $2 \mathrm{~h}$ at $37^{\circ} \mathrm{C}$. Cells were gently washed once with $1 \times$ PBS and fresh growth medium added. Sixteen hours post-transfection, the medium was replaced with RPMI supplemented with 5\% fetal bovine serum, unless otherwise stated, and incubated at $5 \% \mathrm{CO}_{2}$ for $24 \mathrm{~h}$ prior to the initial collection of viral supernatant. A second collection was made after a further $24 \mathrm{~h}$. The conditioned medium from the 2 harvests was combined with sedimentation of cells/debris for $15 \mathrm{~min}(1620 \mathrm{~g})$ followed by ultracentrifugation of the supernatant for $2 \mathrm{~h}$ $(70,409 \times \mathrm{g})$. The pellet containing the viral particles was resuspended in $1 \times$ PBS $(50-100 \mu \mathrm{l})$ and stored at $-80^{\circ} \mathrm{C}$. The titer of viral particles was assessed with a 2-sided sandwich enzyme-linked immunosorbent assay for $\mathrm{p} 24$, as previously described [26]. Lentiviral infectivity was determined by GFP expression 24 and $48 \mathrm{~h}$ post-transfection (HEK293FT cells or primary neuronal cultures) as described (for details see [31]). The fraction of infected cells was measured by flow cytometry (BD FACS Aria I; BD Biosciences, San Jose, CA, USA), which sorted cells expressing GFP from those lacking fluorescence. Also, 6 to 9-day-old primary neuronal cultures were exposed to lentiviral vectors for 48 $\mathrm{h}$, followed by fixation of the tissue with paraformaldehyde (PFA; $4 \%$ in $0.1 \mathrm{M}$ PBS). After extensive rinses $(3 \times 15 \mathrm{~min}$ in $1 \times$ PBS), samples were air-dried and cover-slipped in Vectashield mounting medium with 4',6-diamidino-2phenylindole (H-1500; Vector Laboratories, Burlingame, CA, USA) and image acquisition using a confocal microscope.

\section{Targeting Lentiviral Vectors}

Sulfo-NHS-SS-Biotin (cat. \# 21328; Thermo Fisher Scientific, Waltham, MA, USA) was used for lentivirus biotinylation, in line with the manufacturer's instructions. In brief, streptavidin was dissolved in ultrapure $\mathrm{dH}_{2} \mathrm{O}(10 \mu \mathrm{g} / 1$ $\mu \mathrm{l}$ ) and added to lenti-GFP at a 40-fold molar excess based on vesicular stomatitis virus glycoprotein $\mathrm{G}$ (VSV-G; $70 \mathrm{Kd}$ ) with incubation at $4^{\circ} \mathrm{C}$ for $2 \mathrm{~h}$. Nonreacted sulfo-NHS-SSBiotin was removed by dialysis (12-14 k molecular weight cut-off) in $1 \times \mathrm{PBS}\left(\mathrm{pH} \mathrm{7.4)}\right.$ ) at $4^{\circ} \mathrm{C}$ overnight. The amount of biotin bound to the lentivirus was estimated with 4'hydroxyazobenzene-2-carboxylic acid/avidin reagent (cat. \# H2153; Sigma-Aldrich, St. Louis, MO, USA), using a Pierce calculator (http://www.piercenet.com/haba/habacalcmp.cfm). The Link conjugation kit (cat, \# 708-0015; Innova Biosciences, Cambridge, UK) was used to conjugate streptavidin $(10 \mu \mathrm{g})$ to anti-p75 antibody $(10 \mu \mathrm{g}$; cat. \# 07 476, Millipore, Billerica, CA, USA) in $100 \mu \mathrm{l}$ amine-free buffer (10-50 mM, pH 6.5-8.5). Following overnight incubation at RT, quencher reagent $[1 \mu \mathrm{l}$; supplied in kit, cat. \# 708-0015 (Innova Biosciences)] was added for $30 \mathrm{~min}$ at RT. Biotinylated lentivirus $\left(5 \times 10^{6}\right.$ lentiviral particles $)$ was combined with streptavidin conjugated anti-p75 $(10 \mu \mathrm{g})$ $\mathrm{IgG}$ and incubated for $5 \mathrm{~h}$ at RT. The effectiveness of conjugation was verified by sodium dodecyl sulfate polyacrylamide gel electrophoresis and Western blotting (12\% polyacrylamide gels). Targeted material was tested for infectivity in rat primary neuronal cultures $\left(2 \mu \mathrm{l} ; 9.0 \times 10^{6} \mathrm{IUs} / \mathrm{ml}\right)$, as specified [31, 32].

\section{Stereotactic Surgery with Intraventricular Injection of Viral Vectors and Cy3-IgG ${ }^{192}$}

Surgical procedures for stereotactic injections were approved by the research ethics and biosafety committees of DCU. Prior to surgery, rats were immobilized in the stereotactic frame with their heads fixed (Stoelting, Wood Dale, IL, USA). Experiments were conducted under general anesthesia (ketamine, $50 \mathrm{mg} / \mathrm{kg}$ i.p.), as described previously, and the depth of anesthesia monitored throughout the surgery. The anti-p $75^{\mathrm{NTR}}$ antibody targeted lentivirus (total volume $5 \mu \mathrm{l} ; 7 \times 10^{7} \mathrm{IUs} / \mu \mathrm{l}$ ) was injected unilaterally $(0.2 \mu \mathrm{l} / \mathrm{min})$ into the ventricle (anterio-posterior $=-0.8$, mediolateral $=1.2$ from Bregma and dorso-ventral $=3.0 \mathrm{~mm}$ depths) [33]. Control animals were treated similarly except that they were injected with saline $(0.9 \% \mathrm{NaCl})$ or nontargeted lenti-GFP (total volume $\left.5 \mu \mathrm{l} ; 7 \times 10^{7} \mathrm{IUs} / \mu \mathrm{l}\right)$. Similar stereotactic settings were applied for injection of $5 \mu \mathrm{l}$ anti-p $75^{\mathrm{NTR}}$ 192-IgG conjugated with cyanide dye Cy3 (Cy3-IgG ${ }^{192}$ ) (Advanced Targeting Systems, USA). Postinjected animals were returned to the bioresource facility and allowed to recover. Subsequently, the rats were euthanized with sodium pentobarbital (Euthatal, 200 $\mathrm{mg} / \mathrm{kg}$ i.p.; Pfizer, New York, NY, USA) and perfused with 150 $\mathrm{ml} 0.1 \mathrm{M}$ PBS (pH 7.4), followed by $100 \mathrm{ml}$ 4\% PFA (pH 7.4). The brains were removed and postfixed in $4 \%$ PFA at $4^{\circ} \mathrm{C}$ overnight, cryoprotected with $30 \%$ sucrose in $0.1 \mathrm{M}$ PBS, and sectioned coronally at a thickness of $35 \mu \mathrm{m}$ on a freezing microtome (CM3050 S; Leica, Wetzlar, Germany).

\section{Immunohistochemistry and Confocal Microscopy}

For histochemistry and fluorescence microscopic detection of prelabeled neurons, brains containing rostral portions of $\mathrm{BF}$ were prepared as described elsewhere [28]. Briefly, the freefloating sections were collected in 0.1 M PBS ( $\mathrm{pH} 7.4$ ) with $0.1 \% \mathrm{NaN}_{3}$ (cat. \# 438456; Sigma-Aldrich), washed 3 times in $0.1 \mathrm{M}$ PBS before incubation in $0.4 \%$ Triton X-100 (cat. \# T9284; Sigma-Aldrich) diluted in 0.1 M PBS for $1 \mathrm{~h}$ in darkness at RT. After 3 washes in $0.1 \mathrm{M}$ PBS, the tissue was kept in blocking solution containing 5\% bovine serum albumin and $2 \%$ rabbit serum for $1 \mathrm{~h}$, followed by exposure to a goat polyclonal antibody against choline acetyltransferase (ChAT) (cat. \# AB144P; Millipore) at 1:100 dilutions in the presence of $0.4 \%$ Triton X-100 in 0.1 M PBS (overnight, RT). Slices 
were then rinsed with 3 changes of $0.1 \mathrm{M}$ PBS ( 5 min each) before incubation with rabbit antigoat $\mathrm{H}+\mathrm{L}$ secondary antibody labeled with fluorescein isothiocyanate (cat. \# ab6737; Abcam, Cambridge, UK) at 1:1000 dilution in 0.1 M PBS. For double labeling of ChAT and parvalbumin (PV; $\gamma-$ aminobutyric acid-ergic neuronal marker), the same procedure was applied followed by a blocking step with $10 \%$ rabbit serum in $0.1 \mathrm{M}$ PBS for $30 \mathrm{~min}$ before the addition of $5 \%$ bovine serum albumin and $2 \%$ goat serum containing $0.4 \%$ Triton X-100 in 0.1 M PBS for $1 \mathrm{~h}$. This was followed by exposure of brain slices to anti-PV antibody (cat. \# P3088; Sigma-Aldrich) at a 1:250 dilution, overnight at RT. Staining with Alexa Fluor 594 secondary antibody (cat. \# A11005; Life Technologies, Carlsbad, CA, USA) diluted at 1:2500 in 0.1 M PBS was performed for $1 \mathrm{~h}$, after extensive rinsing of the primary IgG. For double labeling of ChAT and GFP, slices were stained for ChAT as described above except that rabbit antigoat $\mathrm{H}+\mathrm{L}$ secondary antibody with Alexa Fluor 594 (cat. \# A-11080; Thermo Fisher Scientific) at a 1:1000 dilution in $0.1 \mathrm{M}$ PBS was used. This was followed by exposure of brain slices to rabbit polyclonal antibody to GFP (cat. \# ab290; Abcam) at a 1:250 dilution, overnight at RT, followed by staining with goat antirabbit $\mathrm{H}+\mathrm{L}$ secondary antibody labeled with FITC (cat. \# ab6717; Abcam) diluted at 1:2500 in 0.1 M PBS for $1 \mathrm{~h}$, after extensive rinsing of the primary IgG. Procedures for prelabeling of $\mathrm{BF}$ cholinergic neurons with Cy3-IgG ${ }^{192}$ in vivo, followed by ChAT staining were described elsewhere [28]. After air-drying, slices were covered with Vectashield hardset medium (H-1500; Vector Laboratories). An internal control for the staining involved omitting the primary antibody and inclusion of only the relevant secondary antibody. Fluorescence micrographs were obtained ( $\times 40$ objective) using a laser scanning microscope in epifluorescence mode (pinhole wide open; AxioObserver, Carl Zeiss, Jena, Germany). Argon and helium/neon lasers provided the $\mathrm{A} 488_{\mathrm{nm}}$ and $\mathrm{A} 568_{\mathrm{nm}}$ lines for excitation; the emitted signals were sampled in a frame mode at spatial resolution of $30 \mathrm{~nm}$ per pixel with a $1.5-\mu \mathrm{s}$ dwell time. Neuron counting was performed on fluorescence micrographs using Image $\mathbf{J}$ (National Institutes of Health, Bethesda, MD, USA) with a threshold-based approach [31].

\section{Electrophysiological Recordings from BF Cholinergic Cells}

Cy3-IgG ${ }^{192}$ or GFP-encoding lentivirus preinjected rats were used for electrophysiological recordings. Under deep general anesthesia (ketamine: $120 \mathrm{mg} / \mathrm{kg}$; xylasine: $10 \mathrm{mg} / \mathrm{kg}$ ), rats were decapitated, the brains removed rapidly and placed in ice-cold artificial cerebrospinal fluid containing sucrose 75 $\mathrm{mM}, \mathrm{NaCl} 85 \mathrm{mM}, \mathrm{KCl} 2.5 \mathrm{mM}, \mathrm{NaH}_{2} \mathrm{PO}_{4} 1.25 \mathrm{mM}$, $\mathrm{NaHCO}_{3} 25 \mathrm{mM}, \mathrm{CaCl}_{2} 0.5 \mathrm{mM}, \mathrm{MgCl}_{2} 4 \mathrm{mM}$, and glucose $25 \mathrm{mM}$ (pH 7.4), continuously bubbled with $95 \%$
$\mathrm{O}_{2}$ and $5 \% \mathrm{CO}_{2}$. Slices $(300 \mu \mathrm{m}$, coronal plane) were cut and transferred for $30 \mathrm{~min}$ incubation at $32^{\circ} \mathrm{C}\left(95 \% \mathrm{O}_{2} / 5 \%\right.$ $\mathrm{CO}_{2}$ bubbling) in the same solution, except that sucrose was omitted and the concentration of $\mathrm{Na}^{+}$increased to $125 \mathrm{mM}$. Subsequently, they were transferred to recording in artificial cerebrospinal fluid $\left(\mathrm{NaCl} 125 \mathrm{mM}, \mathrm{KCl} 2.5 \mathrm{mM}, \mathrm{NaH}_{2} \mathrm{PO}_{4}\right.$ $1.25 \mathrm{mM}, \mathrm{NaHCO}_{3} 25 \mathrm{mM}, \mathrm{CaCl}_{2} 2 \mathrm{mM}, \mathrm{MgCl}_{2} 2 \mathrm{mM}$, and glucose $25 \mathrm{mM}$ ), where they were kept under continuous bubbling at RT until used. Recordings were made in the environmental chamber fixed to the stage of an Olympus microscope (BX51; Olympus, Tokyo, Japan) under continuous perfusion (1-2 ml/min). Cy3- and GFP-positive cells of medial septum (MS) and diagonal band Broca (DBB) nuclei were visualized using differential interference contrast and fluorescence optics. GFP or Cy3 were excited at A488 and $\mathrm{A} 543_{\mathrm{nm}}$ wavelengths, respectively; images (12 bit) were obtained with $40 \times$ water dipping objective with a chargecoupled device camera (Quantix 57; Roper Scientific, Planegg, Germany) mounted on the microscope. Cy3$\mathrm{IgG}^{192}$ and/or GFP-labelled neurons were analyzed. Patch pipettes were pulled from borosilicate glass capillary tubing (P97 puller; Sutter Instruments, Novato, CA, USA). For cell-attached experiments, electrodes were filled with filtered extracellular solution; for whole-cell experiments, an internal solution of the following composition was used: $\mathrm{KCH}_{3} \mathrm{O}_{3} \mathrm{~S}$ $140 \mathrm{mM}, \mathrm{KCl} 5 \mathrm{mM}, \mathrm{NaCl} 5 \mathrm{mM}, \mathrm{MgATP} 2 \mathrm{mM}$, ethylene glycol tetraacetic acid $0.01 \mathrm{mM}$, HEPES $10 \mathrm{mM}$, and Trisguanosine triphosphate $0.3 \mathrm{mM}(\mathrm{pH} 7.2)$. All recordings were obtained in current-clamp mode (EPC10 USB; HEKA, Ludwigshafen, Germany). Cell-attached configuration was established by placing the tip of the recording pipette in proximity to the soma of the neuron of interest followed by application of weak negative pressure to facilitate the development of a loose seal $(50 \Omega \mathrm{M})$ [34]. In wholecell experiments, after Giga-seal formation, the membrane was ruptured and the electrode capacitance and series resistance measured under voltage-clamp mode; the amplifier was then switched into current clamp mode for monitoring the evoked membrane responses. The output signals of both cell-attached and whole-cell experiments were filtered at $10 \mathrm{kHz}$ and saved for off-line assessments. The membrane capacitance and resistance were tabulated for further calculations and comparison. Evoked responses were induced by stimulation of neurons with rectangular depolarizing current pulses (30-pA increments; $1 \mathrm{~s})$ from hyperpolarized holding potentials (close to $-65 \mathrm{mV}$ ) maintained by steady direct current injection.

\section{Data Analysis and Statistics}

Data are reported as means $\pm \mathrm{SD}$ with statistical significance estimated using paired or unpaired Student's $t$ test. The difference between samples was defined as significant if $p<0.05$. 


\section{Results}

Within the BF, cholinergic neurons are densely intermingled with $\gamma$-aminobutyric acid-ergic, glutamatergic, and peptidergic neurons. In rostral BF nuclei, the vast majority $(>95 \%)$ of cholinergic cells are enriched with $\mathrm{p} 75^{\mathrm{NTR}}[35$, 36]. Figure 1(A) illustrates coronal forebrain slices containing MS and vertical limb of DBB nuclei immunostained for ChAT and PV. In line with published literature, within the MS, ChAT-positive cholinergic cells mainly occupy lateral areas, while in the vertical limb of DBB they reside predominantly within medioventral portions. We, and others, have shown the extent of labeling of the MS and DBB cholinergic neurons (ChAT-positive) with anti-p75 ${ }^{\mathrm{NTR}} \mathrm{Cy} 3-\mathrm{IgG}^{192}$ in young (23 -week-old) Sprague-Dawley rats [28, 37-39]. To verify if similar labeling of ChAT-positive cells occurs with Cy3$\mathrm{IgG}^{192}$ in young adult rats, with $\mathrm{Cy} 3-\mathrm{IgG}^{192}$-positive neurons exhibiting a neurophysiological phenotype of cholinergic cells, 6-8-week-old animals were injected with $\mathrm{Cy} 3-\mathrm{IgG}^{192}$ and processed for microscopic analysis and electrophysiology (Figs 1B-D and 4D-G). In both fixed $(30 \mu \mathrm{m})$ and live (300 $\mu \mathrm{m})$ slices ( $n=3$ and $n=6$ animals per group, respectively), numerous Cy3-labeled neurons could be seen in the injected and contralateral sides, which, with no exception, were also immune-reactive for ChAT (Fig. 1B). Assessments of the electrophysiological characteristics of $\mathrm{Cy} 3$-labeled neurons with cell-attached or whole-cell recordings revealed spontaneous or evoked firing activity similar to that reported previously in BFCNs [40-43]. In acute brain slices, approximately a third of Cy3-positive cells $(6 / 21 ; 28.5 \%)$ revealed slow and irregular firing under cell-attached recording, with the rest electrically silent $(15 / 21 ; 71.5 \%)$ but firing transiently under depolarizing conditions $\left(30 \mathrm{mM}\right.$ extracellular $\mathrm{K}^{+}$; data not shown). This pattern contrasts with spontaneous firing of noncholinergic cells (i.e., $\mathrm{Cy} 3-\mathrm{IgG}^{192}$-negative), which displayed higher and more regular discharge characteristics [26, 28]. Under whole-cell recording, Cy3-positive neurons responded to direct depolarization either by 1) delayed-onset repetitive discharge (Fig. 1D), or 2) rapidly adapting firing [9/ $16(56.3 \%)$ and $7 / 16(43.8 \%) ; n=5]$, in agreement with previous reports [43].

To find out if anti-p $75^{\mathrm{NTR}} \operatorname{IgG}$ can facilitate transduction of viral vectors to BFCNs, we prepared naïve and anti-p $75^{\mathrm{NTR}}$ antibody-coated (targeted) vectors encoding reporter GFP (Figs 2 and 3). The infectivity of the material was confirmed in HEK293FT cells and in cultured cortical neurons, using fluorescence microscopy and fluorescence-activated cell sorting (Fig. 2C-G). Effective transduction with expression of GFP occurred under both settings $48 \mathrm{~h}$ after exposing cultures to the naive virus, with a dose-dependent increase in transduction of HEK293FT cells verified (Fig. 2C, D). The broad tropism with infectivity of nontargeted vectors was also demonstrated in neuronal cultures in vitro and by injections of the material into ventral pallidium and hippocampal dentate gyrus in vivo. Six to 8 days postinjection $\left(10^{7}\right.$ viral particles per $2.5 \mu \mathrm{l} ; n=3$ per group), animals were perfused and the
A

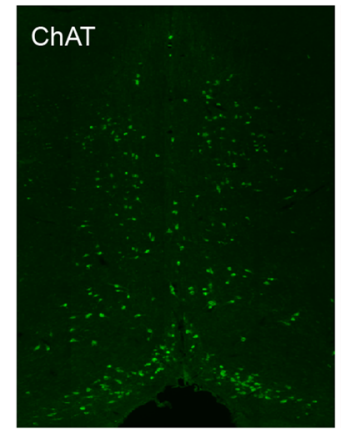

$\mathrm{B}$
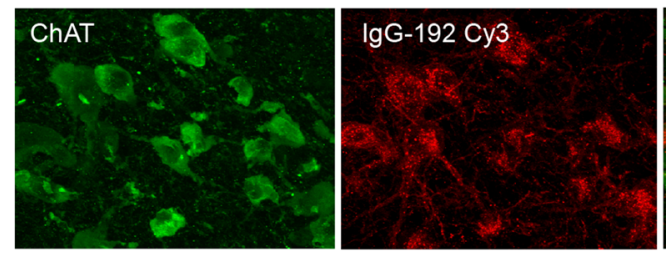
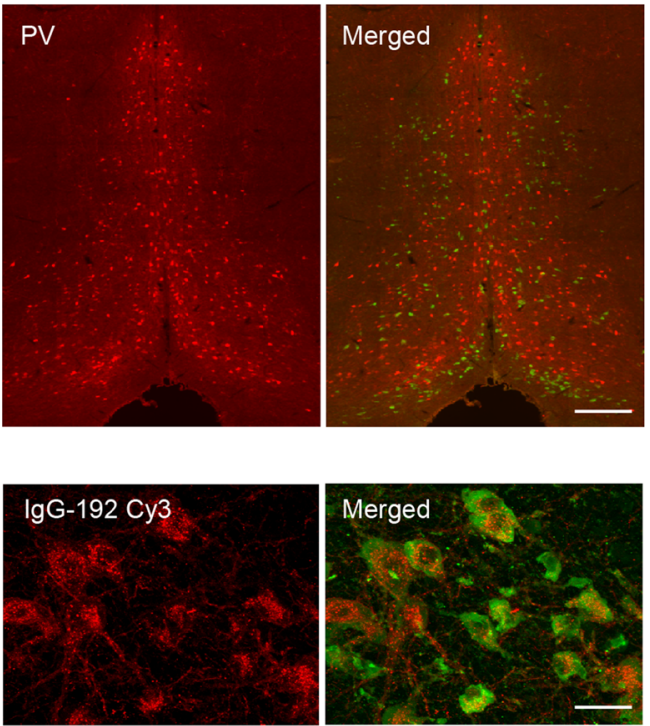

C

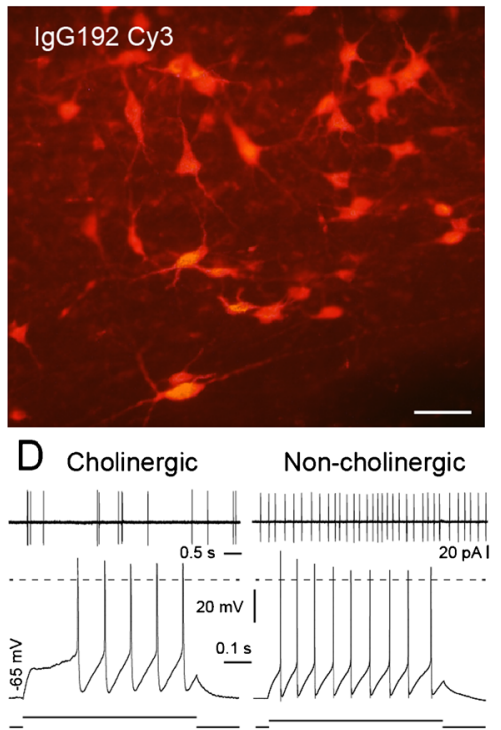

Fig. 1 (A) Fluorescent micrographs of forebrain sections at the level of the medial septum and diagonal band Broca (coronal plane), showing anticholine acetyltransferase (ChAT) and antiparvalbumin (PV) antibody-labeled neurons (left and middle, respectively) and their merged representation (right panel). Scale bar $=100 \mu \mathrm{m}$. (B) Double anti-ChAT antibody and $\mathrm{Cy} 3-\operatorname{IgG}{ }^{192}$-stained neurons of horizontal limb of the diagonal band Broca (green and red, respectively) with their merged representation (right panel). Scale bar $=20 \mu \mathrm{m}$. (C) Cholinergic neurons prelabeled in vivo with intracerebroventricular injection of Cy3-IgG ${ }^{192}$ : thick $(300 \mu \mathrm{m})$ acute slice (live epifluorescence image). Scale bar $=30$ $\mu \mathrm{m}$. (D) Representative recordings of spontaneous and evoked firing activity of cholinergic (left pair, Cy3-positive) and noncholinergic (right pair, Cy3-negative) neurons under cell-attached and whole-cell conditions (top and bottom, respectively) 
Fig. 2 (A, left) Schematic of a retroviridae lentivirus containing single-stranded RNA (dark blue) enclosed within a p24 capsid (amaranth pink) and glycoprotein envelope (aqua); (right) Western blot of p24 capsid detected from denatured lentivirus. Lane 1: precision plus protein ladder; lane 2: band of $24 \mathrm{kD}$ (arrow) representing p24 lentiviral capsid protein. Maps of plasmids used for production of second-generation lentivirus. (1) pMD-2G (for envelope); (2) pWPI-green fluorescent protein (GFP; for transfer), and (3) pCMV-d-8.74 (for packaging) (lower left). Details reported previously in [31]. (B) Electrophoresis of restriction enzyme-digested plasmids with uncut counterpart separated on a $2 \%$ Tris-borate-ethylenediaminetetraacetic acid agarose gel, 1-kb ladder (Invitrogen, Carlsbad, CA, USA) (unmarked left lane). Lanes 1 and 2: pWPI-GFP (9.5 kb) undigested and BamH1 digested, respectively. Lanes 3 and 4: pMD-2D (5.8 kb) undigested and Pst 1 digested, respectively. Lanes 5 and 6: pCMV-d-8.74 (12 kb) undigested and EcoR1/ $X h o R 1$ digested, respectively. (C, D) A typical culture of transfected HEK293FT cells verifying the infectivity of nontargeted lentiviral material (C), with cell sorting and counting (fluorescence-activated cell sorting) illustrating dose dependency of the GFP transduction of HEK293FT cells exposed to different titers of viral particles. 4',6-Diamidino-2-phenylindole (DAPI) was used for nuclear staining. Scale bar $=20 \mu \mathrm{m}$. (E-G) Immunohistochemical validation of brain forebrain (BF) neuronal cultures containing choline acetyltransferase (ChAT)-positive cholinergic neurons (E) with their transduction with GFP using nontargeted GFP encoding vectors $(\mathrm{F}, \mathrm{G})$. (G) Note the transduction of Cy3-IgG ${ }^{192}$-positive neuron in vitro. Scale bars $=25 \mu \mathrm{m}(\mathrm{left})$ and $15 \mu \mathrm{m}$ (middle and right). (G, H) Fluorescence micrographs of GFP-expressing neurons within the ventral pallidal (VP) region and hippocampal dentate gyrus (DG). Scale bar $=30 \mu \mathrm{m}$

expression of GFP verified (Fig. 2H, I). In all cases, a strong focal transduction at the site of injection was evident, with GFP enriched in neuronal somata and processes, as well as in glia. It is worth noting that intraventricular injection of nontargeted GFP-encoding vectors also caused pronounced labeling of the cells of ventricular wall and underlying glial, with sparse GFP-positive neurons also scattered within the adjacent dorsolateral and medial portion of caudate nucleus. In MS and DBB nuclei, the vast majority of sparse GFPlabeled cells were ChAT positive and constituted $\sim 5 \%$ and $\sim 0.4 \%$ of the cholinergic cell population, respectively $(n=3$, 6 weeks postinjection) (see Fig. 5D).

To assess whether coating GFP-encoding vector with anti$\mathrm{p} 75^{\mathrm{NTR}}$ IgG facilitates transduction of GFP to BFCNs, as a first step viral particles were biotinylated with sulfo-NHS-SSBiotin. Next, conjugation of streptavidin to anti-p $75^{\mathrm{NTR}} \mathrm{IgG}$ was achieved using the Link commercial kit. All steps of these reactions were monitored using biochemical assays (Fig. 3A, B). It is worth stressing that anti-p $75^{\mathrm{NTR}} \mathrm{IgG}$ offers a better choice for targeting viral vectors to BFCNs than NGF, because, firstly, biotinylation of NGF is known to reduce its binding activity to neurotrophin receptors [45], and, secondly, in addition to $\mathrm{p} 75^{\mathrm{NTR}}$ enriched in cholinergic neurons, NGF also binds the TrkA receptor expressed on cholinergic neurons and other cells $[46,47]$. Conjugates of anti-p $75^{\mathrm{NTR}}$ IgG with small fluorescence probes and neurotoxic peptides have been shown to target and facilitate their effects in BFCNs [29, 30, 48]. Hartig et al. [37] also showed that $\mathrm{Cy} 3$ bound to $\operatorname{IgG}^{192}$ selectively labeled BFCNs and stayed within these neurons over several months [37], while IgG $^{192}$ conjugates of ribosome inhibitor peptide saporin have been widely used for their lesions [22, 27, 29, 30]. Importantly, neither saporin nor Сy3 linked to $\mathrm{IgG}^{192}$ hindered its binding to $\mathrm{p} 75^{\mathrm{NTR}}$ or internalization by BFCNs. These reports suggest that the mechanisms of uptake or retroaxonal transport of $\mathrm{p} 75^{\mathrm{NTR}}$ in BFCNs exposed to $\mathrm{Cy} 3-\operatorname{IgG}^{192}$ or saporin $\operatorname{IgG}^{192}$ remain operational and can possibly be used for targeting and delivery of vectors to these cells.

Under our settings, intraventricular injection of antip $75^{\text {NTR }}$ IgG-targeted vectors $\left(10^{7}\right.$ viral particles per $5 \mu \mathrm{l} ; 3$ groups with 5 in each group) was followed by a recovery period (2, 4 and 6 weeks) with subsequent perfusion and examination of GFP-labeled neurons in slices at 3 postinjection time points (Fig. 4 A-E). To verify if conjugation of GFPencoding vectors with anti-p $75^{\mathrm{NTR}}$ antibody can afford transduction of GFP in BFCNs, a subset of animals also received an additional intracerebroventricular injection of $\mathrm{Cy} 3-\mathrm{IgG}^{192}$ ( $n=3-4$ /group). It is important to note that the cytotoxic effects of saporin- $\operatorname{IgG}^{192}$ on BFCNs implicate a release of saporin from endocytotic compartments. As shown in Fig. 4 $(\mathrm{B}, \mathrm{C})$, in animals injected with targeted vectors, GFP labeling was readily visible along the needle track through the motor cortex (M2) with distinctive green fluorescence also present within the ventral portion of the corpus callosum and the ventricular wall. Most importantly, in addition to sparse green neurons scattered within the dorsal septum, ventral areas of pallidum and caudate areas, the neurons of MS, DBB, and the more caudal preoptic nucleus exhibited dramatically enhanced GFP labeling (Fig. 4D). Counting of GFP-Cy3 double-labeled neurons at various postinjection time points revealed that all GFP-positive BFCNs in MS and DBB nuclei also labeled positive for $\mathrm{Cy} 3-\mathrm{IgG}^{192}$. Notably, the level of double labeling of cells was markedly lower at the first point of evaluation, and increased over a longer postinjection time (Fig. 4E). Such dynamics are likely to reflect a gradual increase in the GFP signal in transduced neurons, due to the accumulation of GFP in BFCNs. Analysis of the bioelectrical activity and passive properties of GFP-labeled neurons revealed a close match with those of only $\mathrm{Cy} 3-\mathrm{IgG}^{192}$-labeled cells. Like Cy3labeled cells, a considerable fraction of GFP-positive neurons showed slow and irregular spontaneous firing under cellattached recordings $[6 / 19(31.6 \%) ; n=5]$, with the rest remaining quiescent $(68.4 \%)$. Under whole-cell conditions, GFP-labeled neurons responded to strong depolarizing pulses with delayed and slow-onset firing or rapidly adapting spikes [8/20 (40\%) and 12/20 (60\%); $n=5]$. Comparison of passive membrane properties of GFP- and Cy3-positive cells also unveiled their overlap (Fig. 4G, H), confirming that these represent the same subpopulation of neurons. To verify explicitly the cholinergic phenotype of GFP-positive cells, MS- and 


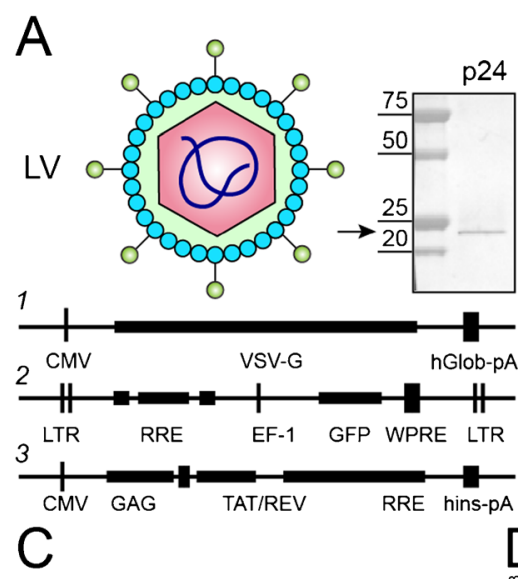

B

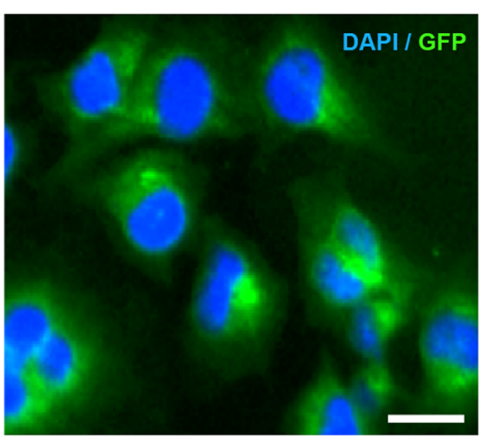

$E$
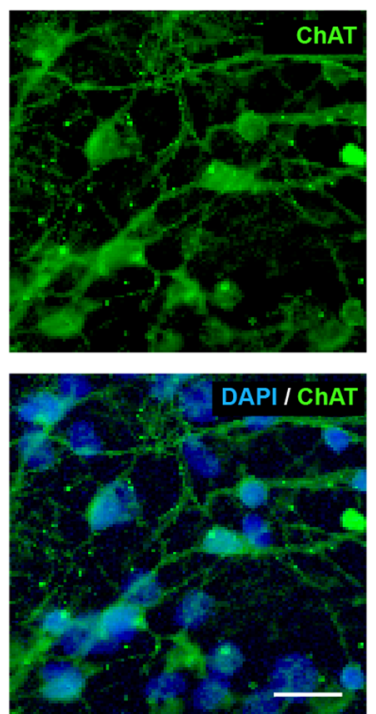

$\mathrm{H}$

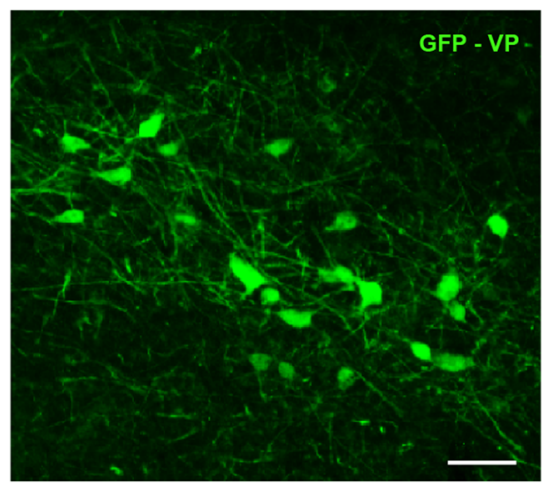

F
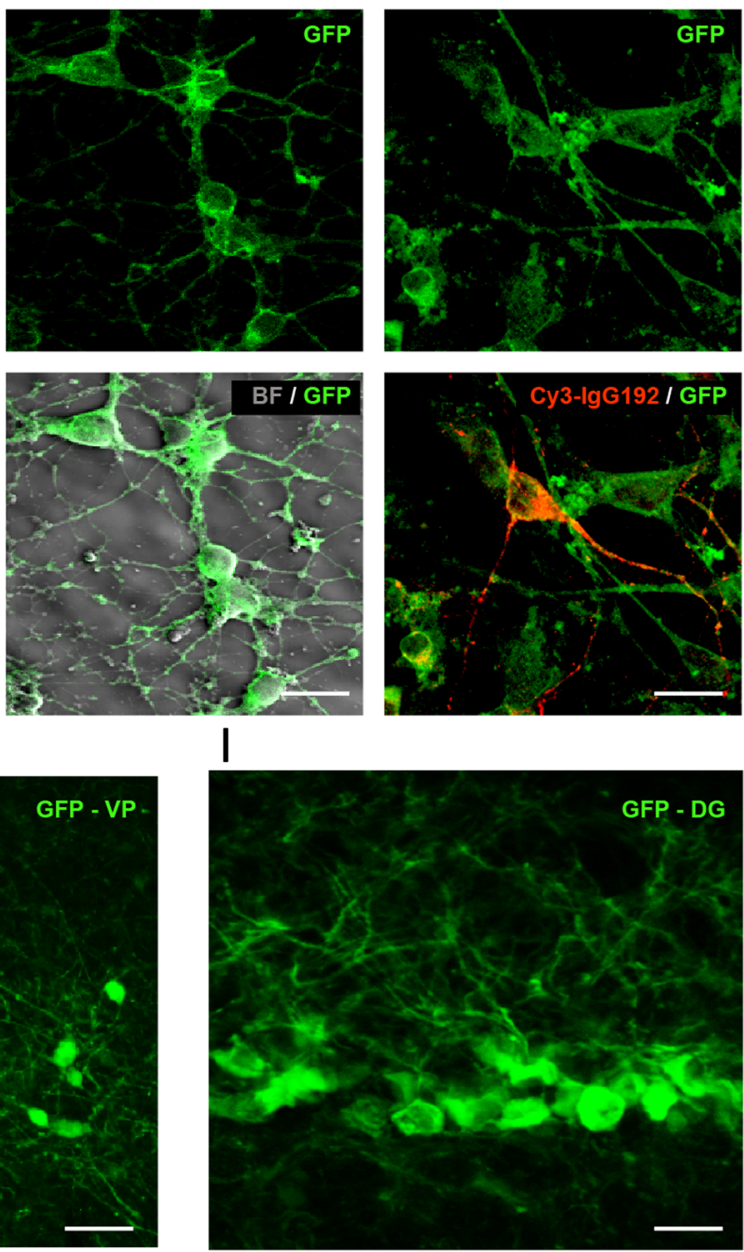

G
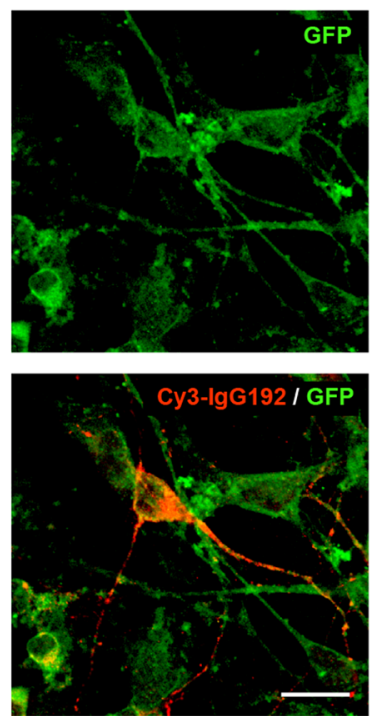
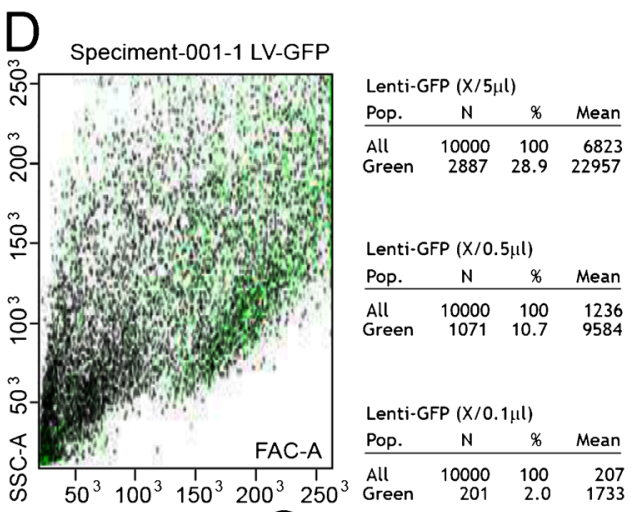

\section{.}



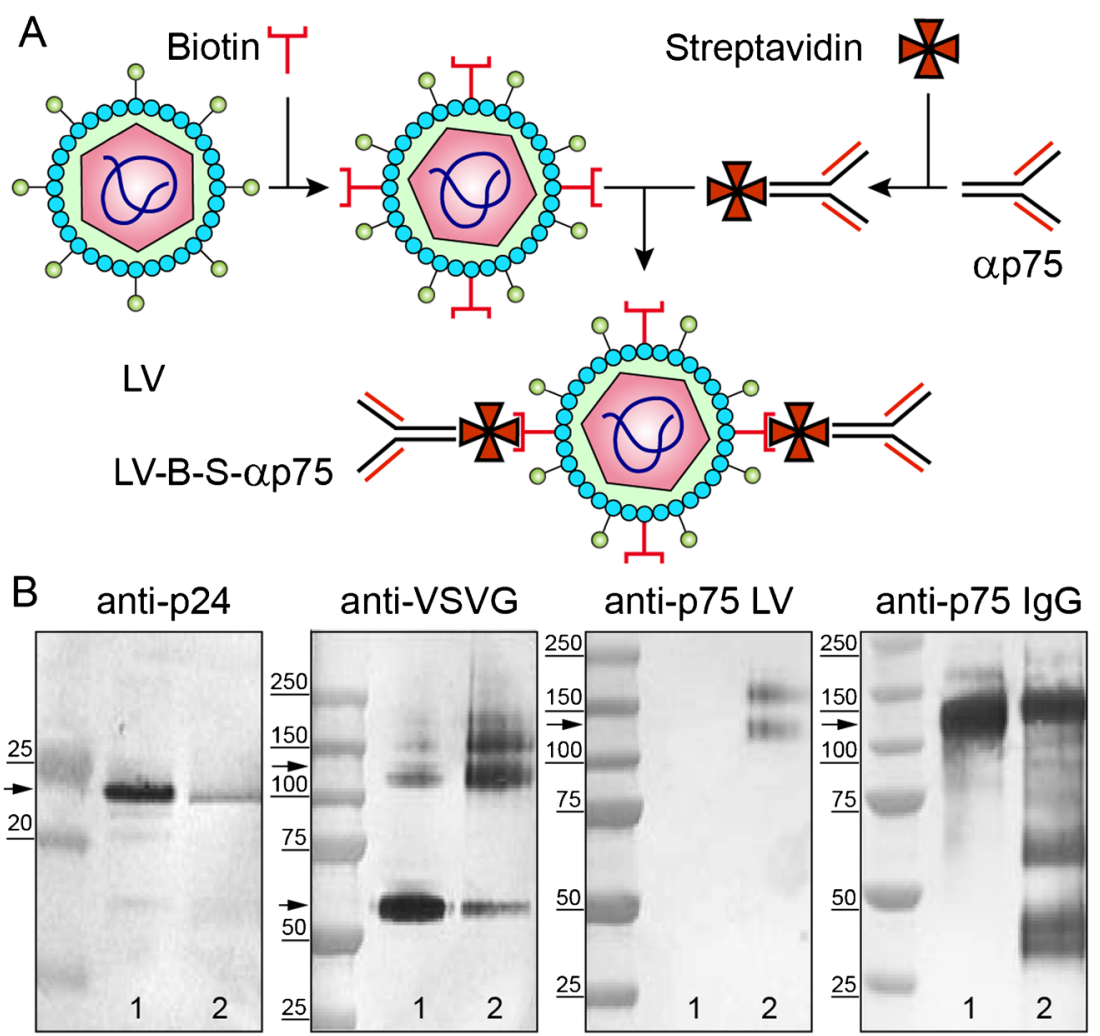

Fig. 3 (A) Schematic illustration of the targeting strategy adapted for green fluorescent protein (GFP)-encoding lentiviral (LV) vectors to basal forebrain cholinergic neurons (BFCNs) through their conjugation to anti$\mathrm{p} 75^{\mathrm{NTR}}$ antibody. Biotinylation of lentivirus (LV; left) and covalent linkage to streptavidin (S)-coated anti-p $75^{\mathrm{NTR}}$ antibody ( $\alpha \mathrm{p} 75$; right) to form LV-B-S- $\alpha$ p75 (below). (B) The progression of targeting was verified via electrophoresis through $12 \%$ Bis Tris NuPAGE gels and Western blotting with specific antibodies appropriate to the stage in the procedure. Representative Western blots shown containing Precision Plus protein ladder (Invitrogen, Carlsbad, CA, USA; left position on each blot).

DBB-containing coronal brain slices from animals injected with targeted vectors were double stained for ChAT and GFP (Fig. 5). As illustrated, in both cholinergic nuclei the fraction of GFP-positive neurons was considerably higher in rats injected with targeted vectors $[\sim 88 \%$ and $\sim 76 \%$, respectively $(n=4) ; 6$ weeks postinjection].

\section{Discussion}

Tight envelopment with transvascular barriers and compartmentalized structures make the central nervous system one of the most challenging targets for therapeutic delivery. Owing to the high sensitivity of neurons to chemical and biological insults and their poor accessibility for nonviral vectors, especially in vivo, targeting viruses with transduction of beneficial genes has been viewed as a promising therapeutic strategy. Yet, remaining conceptual and methodical challenges constrained applications of viral technologies to neurobiology
Lane 1: p24 antigen (molecular weight $2 \mathrm{kD}$ ) detected in lenti-GFP (lane 1) and biotinylated lenti-GFP (lane 2). Vesicular stomatitis virus glycoprotein G (VSV-G) protein (molecular weight $57 \mathrm{kD}$ ) detected with antiVSV-G antibody in lenti-GFP (lane 4) and biotinylated lenti-GFP (lane 3). Backbone (fragment of 2 heavy and 2 light IgG chains) of anti-p 75 antibody detected with anti-p75 in the anti-p $75^{\mathrm{NTR}}$ lenti-GFP construct (lane 5) against lenti-GFP (lane 6). Anti-p75 antibody (Millipore, Billerica, MA, USA) before and after streptavidin conjugation (lanes 7 and 8 , respectively)

research and preclinical studies, with their clinical use becoming available only recently $[49,50]$. One of the key objectives of $\mathrm{AD}$ therapy is protection of $\mathrm{BFCNs}$ and synapses from pathological insult, and restoration, or perhaps enhancement, of cholinergic functions [51-53]. Emerging data suggest that an adequate supply of NGF and TrkA mimetics are likely to counter the neurodegenerative process and improve cholinergic functions [54-56]. Even though the outcome of early AD clinical trials with systemic administration of NGF was grossly unfavorable [56, 57], a more discriminatory supply of NGF to BFCNs with tissue grafting led to notable improvements in cognition with neuroprotection $[5,15]$. Thus, successful use of NGF for AD therapy, in addition to keeping low its off-target effects, requires adequate bioavailability to cholinergic neurons, and as such depends on currently available delivery methods. Although these can be achieved by viral targeting to BFCNs, the broad tropism of the majority of vectors conceals risks of collateral effects, even after their intraventricular and direct injection into the BF nuclei. Taking into 

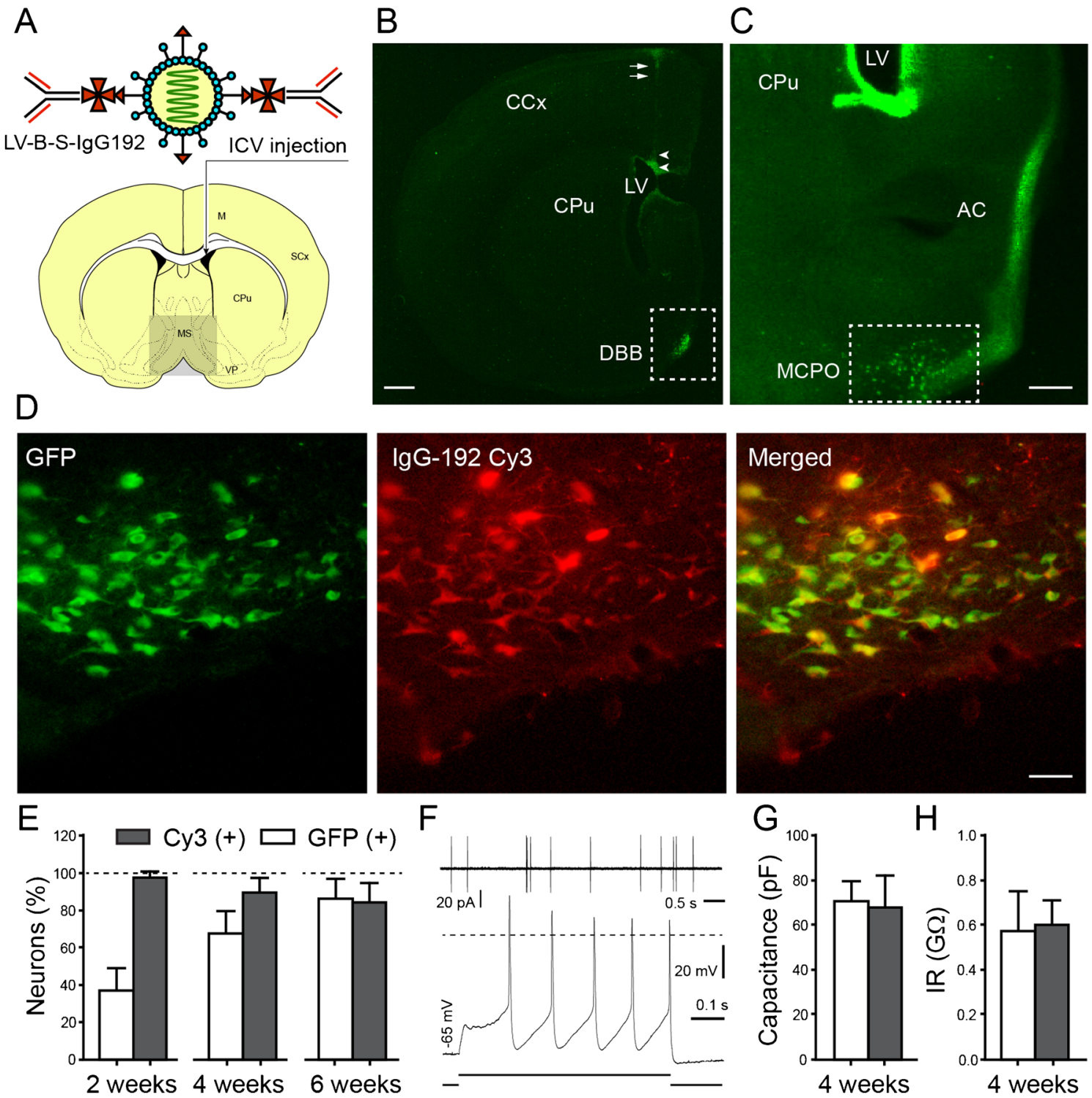

$F$
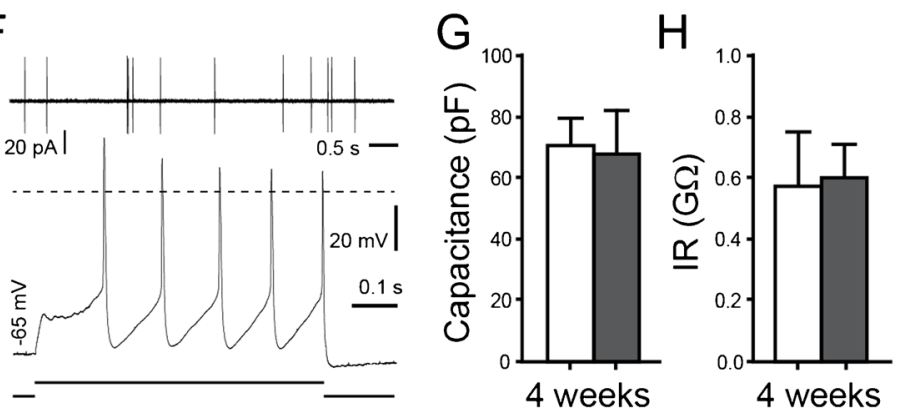

Fig. 4 (A) Schematic illustration of the stereotactic injection of targeted lentiviral (LV) vector (top) into the lateral ventricle [intracerebroventricular (ICV) injection; bottom). (B, C) Low- and medium-magnification images of forebrain slices illustrating the areas with high density of green fluorescent protein (GFP) expression. Note that in addition to strong fluorescence of cells within the cholinergic brain forebrain (BF) region (dashed boxes), strong GFP fluorescence was also visible along the injection track (B, arrows) and in ventral corpus callosum (arrowheads) (B), as well as within the cells of the ventricular wall (C). (D) Double fluorescent (GFPand $\mathrm{Cy}-3$ labeled) neurons (green and red panels) of the horizontal limb of the diagonal band of Broca (DBB) with overlay imaged. (E) Quantitative histograms of cell co-labeling data for medial septum

consideration these premises, we set out to develop a methodology that could enable targeted transduction of lentiviral vectors to BFCNs.

As an enveloped virion with relatively large transgene capacity, lentiviruses are widely utilized for delivery of vectors to neurons in vivo. Low inflammatory and immunogenic characteristics along with minimal toxicity and superior infectivity and diagonal band of Broca nuclei. Note stronger co-labeling of Cy3-positive neurons with GFP reporter at the later time points (4 and 6 weeks). (F) Representative cell-attached and whole-cell recordings of firing activity of GFP-labeled BF cholinergic cells. $(\mathrm{G}$, $\mathrm{H})$ Quantitative histograms of membrane capacitance and input resistance (IR) of Cy3- and GFP-labeled neurons of medial septum and diagonal band of Broca nuclei. The differences between these readouts are insignificant ( $p>0.05$, paired $t$ test) $\mathrm{M}=$ motor cortex; $\mathrm{SCx}=$ somatosensory cortex $; \mathrm{CPu}=$ caudate putamen; $\mathrm{MS}=$ medial septum; VP = ventral pallidum; $\mathrm{CCx}=$ Cerebral Cortex; $\mathrm{AC}=$ nucleus accumbence $; \mathrm{MCPO}=$ Magnocellular Preoptic Nucleus

for terminally differentiated cells render lentiviral vectors especially suitable for delivery of genes into neurons, while their intrinsic capability of integrating transgenes into the genome of host cells with minimal risks for the activation of protooncogenes ensures long-term expression of the genes of interest - a critical condition for treatment of chronic conditions such as $\mathrm{AD}[3,58]$. Despite the fact that lentiviruses belong to 

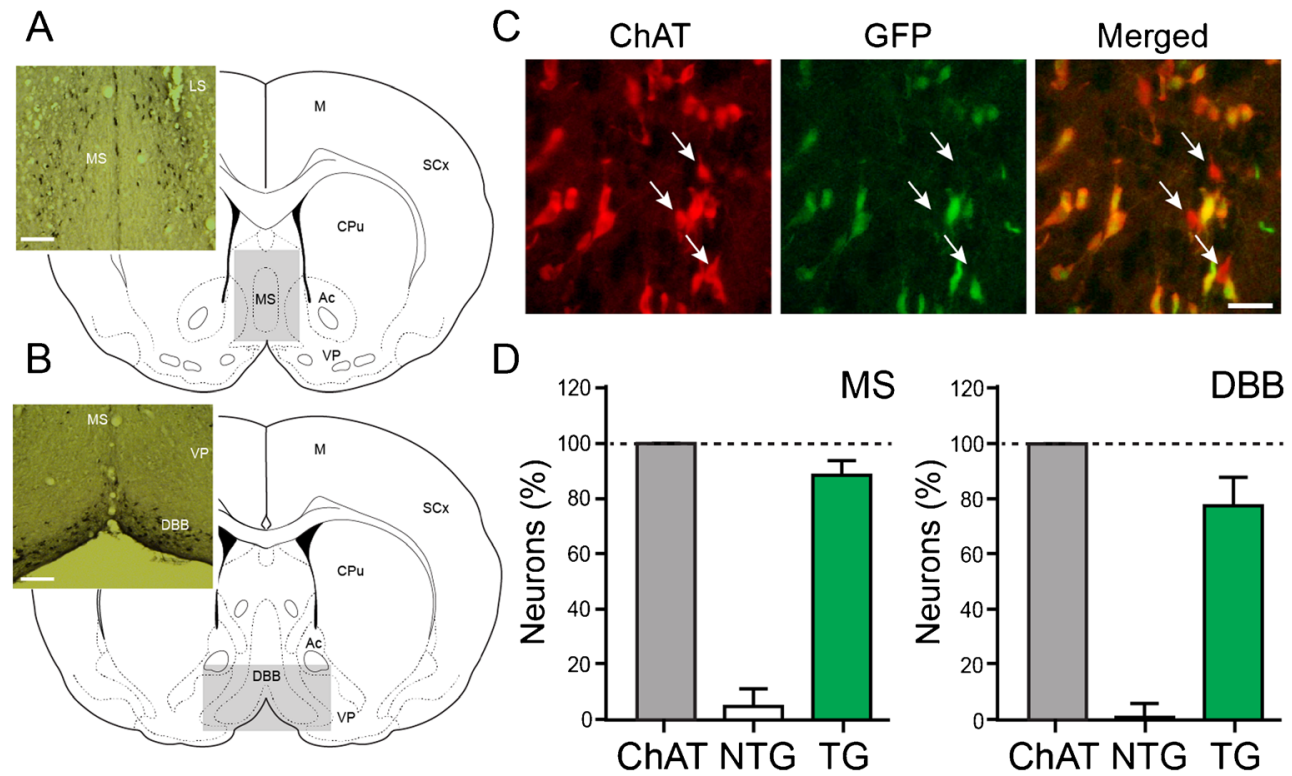

Fig. 5 (A, B) Schematic of coronal brain sections with areas used for cell counting highlighted in gray. The insets show immunostaining, with a horseradish peroxidase method, of cholinergic neurons of the medial septum (MS) and diagonal band of Broca (DBB) nuclei. Description of methodica details in [44]. (C) Double immunofluorescent [choline acetyltransferase (ChAT) and green fluorescent protein (GFP)]-labeled neurons of the MS. Arrows indicate cholinergic neurons nontransduced with

the superfamily of enveloped virions (which include a variety of retroviruses, alphavirus, and herpes simplex virus, with superb intra-axonal mobility) characterized by a long transduction range, the VSV-G pseudotyped vectors used in the present study were shown to exhibit limited intra-axonal mobility $[59,60]$. The latter is in agreement with scant labeling of ependymal cells and few scattered GFP-positive cells of the lateral septum and caudate nucleus after intraventricular injection of GFP-encoding lentiviral vectors. Although short-range trafficking of these vectors cannot be excluded, no retroaxonal transport of lentiviral vectors has been demonstrated, unlike adenoviral systems [61]. We have shown previously that this general "limitation" of lentiviral vectors becomes advantageous after their conjugation with inactive full-length tetanus toxin (TeTIM) or its $\mathrm{H}_{\mathrm{C}}$ binding fragment in keeping the infection at the injection site remaining fairly localized yet capable of longrange propagation with transduction of motor neurons within the spinal cord after peripheral administration [44, 62]. The most parsimonious explanation for such dramatic change in the mobility of vectors linked to TeTIM or $\mathrm{H}_{\mathrm{C}}$ is their targeting of neuronal acceptors linked with fast axonal retrograde transport, which facilitates their propagation from the entry site at nerve terminals to the perikarya of motor neurons. Because $\mathrm{p} 75^{\mathrm{NTR}}$ was implicated in the uptake and retrograde transport of tetanus toxin and its $\mathrm{H}_{\mathrm{C}}$ fragment in motor neurons [63, 64], we reasoned that the same mechanism could also be useful for vector targeting the BFCNs. After all, p $75^{\mathrm{NTR}}$ is strongly enriched in BFCNs in the adult brain, and targeting of cholinergic cells by
GFP. Scale bar $=100 \mu \mathrm{m}$. (D) Summary graphs illustrating the fraction of the GFP-positive neurons from total pools of MS and DBB cholinergic cells. ChAT-positive neurons are taken as $100 \%$ (gray bars) $\mathrm{MS}=$ medial septum; $\mathrm{M}=$ motor cortex $\mathrm{SCx}=$ somatosensory cortex; $\mathrm{CPu}=$ caudate putamen; $\mathrm{Ac}=$ nucleus accumbence; $\mathrm{VP}=$ ventral pallidum; $\mathrm{NTG}=$ nontargeted GFP vectors; $\mathrm{TG}=$ targeted GFP vectors

small peptides or fluorescence probes linked to $\operatorname{IgG}^{192}$ has been utilized for their labeling and destruction in vivo [22, 27, 29, 30, $32,65]$. Our data show that conjugation of vectors with antip $75^{\mathrm{NTR}}$ antibody does, indeed, enable targeted expression of GFP-encoding vectors in BFCNs in adult rat brain.

To achieve tight linkage of anti-p $75^{\mathrm{NTR}}$ to lentiviral vectors, we used streptavidin-biotin conjugation. Owing to the superb affinity $\left(\mathrm{Kd}=10^{-15} \mathrm{M}\right)$ and stability of streptavidinbiotin binding, this reaction has been used in previous studies for targeting viral and nonviral vectors, as well as other cargo, to various cell types [66-69]. It offers considerable advantages over other adaptor systems, affording outstanding stability of targeted materials. Reports of the successful use of streptavidin-bound conjugation of retrovirus with antibodies in other systems proved its suitability for our applications [70, 71], with data presented here extending its use for BFCNs within the intact brain. As pointed out above, AD (and to lesser extent physiological aging) is associated with a deficit of cholinergic functions [21, 54, 72], and, as such, targeted modulation of trophic signaling of BFCNs could be of high benefit. Although discriminatory enhancements of neurotrophic functions of BFCNs is viewed as the prime area of the future application of the described herein method, its use for meddling with other processes also pertinent to the biology and therapy of $\mathrm{AD}$ appears feasible, including modulation of anticholinesterase activity, countering $A \beta$ toxicity, and phosphorylation of tau protein, as well as enhancement of lysosomal and mitochondrial functions. 
Acknowledgments This work was supported by the Program for Research in Third Level Institutions Cycle 4 grant from the Irish Higher Educational Authority for the Neuroscience section of "Targeted-driven therapeutics and theranostics" (JOD and SVO).

Required Author Forms Disclosure forms provided by the authors are available with the online version of this article.

\section{References}

1. Girard A, Verhoeyen E. Lentiviral design and applications. 4th ed. Templeton NS, editor. Boca Raton, FL: CRC Press; 2015. 26 p.

2. Kreppel F. Adeno-virus-mediated gene delivery. 4th ed. Templeton NS, editor. Boca Raton, FL: CRC Press; 2015. 18 p.

3. Davidson BL, Breakefield XO. Viral vectors for gene delivery to the nervous system. Nat Rev Neurosci 2003;4:353-364.

4. Emborg ME, Moirano J, Schafernak KT, et al. Basal ganglia lesions after MPTP administration in rhesus monkeys. Neurobiol Dis 2006;23:281-289.

5. Tuszynski MH, Yang JH, Barba D, et al. Nerve growth factor gene therapy: activation of neuronal responses in Alzheimer disease. JAMA Neurol 2015;72:1139-1147.

6. Bartus RT, Dean RL, 3rd, Beer B, Lippa AS. The cholinergic hypothesis of geriatric memory dysfunction. Science 1982;217:408414.

7. Davies P, Maloney AJ. Selective loss of central cholinergic neurons in Alzheimer's disease. Lancet 1976;2:1403.

8. Mesulam M. The cholinergic lesion of Alzheimer's disease: pivotal factor or side show? Learn Mem 2004;11:43-49.

9. Whitehouse PJ, Price DL, Clark AW, Coyle JT, DeLong MR. Alzheimer disease: evidence for selective loss of cholinergic neurons in the nucleus basalis. Ann Neurol 1981;10:122-126.

10. Bartus RT. On neurodegenerative diseases, models, and treatment strategies: lessons learned and lessons forgotten a generation following the cholinergic hypothesis. Exp Neurol 2000;163:495-529.

11. Borlongan CV. Recent preclinical evidence advancing cell therapy for Alzheimer's disease. Exp Neurol 2012;237:142-146.

12. Kordower JH, Winn SR, Liu YT, et al. The aged monkey basal forebrain: rescue and sprouting of axotomized basal forebrain neurons after grafts of encapsulated cells secreting human nerve growth factor. Proc Natl Acad Sci U S A 1994;91:10898-10902.

13. Martinez-Serrano A, Bjorklund A. Gene transfer to the mammalian brain using neural stem cells: a focus on trophic factors, neuroregeneration, and cholinergic neuron systems. Clin Neurosci 1995;3:301-309

14. Tuszynski MH. Nerve growth factor gene delivery: animal models to clinical trials. Dev Neurobiol 2007;67:1204-1215.

15. Tuszynski MH, Thal L, Pay M, et al. A phase 1 clinical trial of nerve growth factor gene therapy for Alzheimer disease. Nat Med 2005;11:551-555.

16. Mandel RJ, Gage FH, Clevenger DG, Spratt SK, Snyder RO, Leff SE. Nerve growth factor expressed in the medial septum following in vivo gene delivery using a recombinant adeno-associated viral vector protects cholinergic neurons from fimbria-fornix lesion-induced degeneration. Exp Neurol 1999;155:59-64.

17. Vigna E, Cavalieri S, Ailles L, et al. Robust and efficient regulation of transgene expression in vivo by improved tetracycline-dependent lentiviral vectors. Mol Ther 2002;5:252-261

18. Blomer U, Kafri T, Randolph-Moore L, Verma IM, Gage FH. Bcl$\mathrm{xL}$ protects adult septal cholinergic neurons from axotomized cell death. Proc Natl Acad Sci U S A 1998;95:2603-2608.
19. Blesch A, Conner J, Pfeifer A, et al. Regulated lentiviral NGF gene transfer controls rescue of medial septal cholinergic neurons. Mol Ther 2005;11:916-925.

20. Bishop KM, Hofer EK, Mehta A, et al. Therapeutic potential of CERE-110 (AAV2-NGF): targeted, stable, and sustained NGF delivery and trophic activity on rodent basal forebrain cholinergic neurons. Exp Neurol 2008;211:574-584.

21. Counts SE, Mufson EJ. The role of nerve growth factor receptors in cholinergic basal forebrain degeneration in prodromal Alzheimer disease. J Neuropathol Exp Neurol 2005;64:263-272.

22. Heckers S, Ohtake T, Wiley RG, Lappi DA, Geula C, Mesulam MM. Complete and selective cholinergic denervation of rat neocortex and hippocampus but not amygdala by an immunotoxin against the p75 NGF receptor. J Neurosci 1994;14:1271-1289.

23. Ovsepian SV, O'Leary VB, Zaborszky L. Cholinergic mechanisms in the cerebral cortex: beyond synaptic transmission. Neuroscientist 2016;22:238-251.

24. Van der Zee CE, Ross GM, Riopelle RJ, Hagg T. Survival of cholinergic forebrain neurons in developing p75NGFR-deficient mice. Science 1996;274:1729-1732.

25. Ward NL, Hagg T. p75(NGFR) and cholinergic neurons in the developing forebrain: a re-examination. Brain Res Dev Brain Res 1999;118:79-91.

26. Alreja $\mathrm{M}, \mathrm{Wu} \mathrm{M}$, Liu W, Atkins JB, Leranth $\mathrm{C}$, Shanabrough $\mathrm{M}$. Muscarinic tone sustains impulse flow in the septohippocampal GABA but not cholinergic pathway: implications for learning and memory. J Neurosci 2000;20:8103-8110.

27. Berger-Sweeney J, Stearns NA, Murg SL, Floerke-Nashner LR, Lappi DA, Baxter MG. Selective immunolesions of cholinergic neurons in mice: effects on neuroanatomy, neurochemistry, and behavior. J Neurosci 2001;21:8164-8173.

28. Ovsepian SV, Dolly JO, Zaborszky L. Intrinsic voltage dynamics govern the diversity of spontaneous firing profiles in basal forebrain noncholinergic neurons. J Neurophysiol 2012;108:406-418.

29. Rossner S, Hartig W, Schliebs R, et al. 192IgG-saporin immunotoxin-induced loss of cholinergic cells differentially activates microglia in rat basal forebrain nuclei. J Neurosci Res 1995;41:335-346.

30. Wiley RG, Oeltmann TN, Lappi DA. Immunolesioning: selective destruction of neurons using immunotoxin to rat NGF receptor. Brain Res 1991;562:149-153.

31. O'Leary VB, Ovsepian SV, Raghunath A, et al. Innocuous fulllength botulinum neurotoxin targets and promotes the expression of lentiviral vectors in central and autonomic neurons. Gene Ther 2011;18:656-665.

32. Ovsepian SV, Antyborzec I, O'Leary VB, Zaborszky L, Herms J, Oliver Dolly J. Neurotrophin receptor p75 mediates the uptake of the amyloid beta (Abeta) peptide, guiding it to lysosomes for degradation in basal forebrain cholinergic neurons. Brain Struct Funct 2014;219:1527-1541.

33. Paxinos G, Watson C. The rat brain in stereotaxic coordinates. 6th ed. Amsterdam; Boston: Academic Press/Elsevier; 2007.

34. Ovsepian SV, Friel DD. Enhanced synaptic inhibition disrupts the efferent code of cerebellar Purkinje neurons in leaner Cav2.1 Ca 2+ channel mutant mice. Cerebellum 2012;11:666-680.

35. Zaborszky L, Duque A. Local synaptic connections of basal forebrain neurons. Behav Brain Res 2000;115:143-158.

36. Zaborszky L, Pang K, Somogyi J, Nadasdy Z, Kallo I. The basal forebrain corticopetal system revisited. Ann N Y Acad Sci 1999;877:339-367.

37. Hartig W, Seeger J, Naumann T, Brauer K, Bruckner G. Selective in vivo fluorescence labelling of cholinergic neurons containing p75(NTR) in the rat basal forebrain. Brain Res 1998;808:155-165.

38. Kacza J, Grosche J, Seeger J, Brauer K, Bruckner G, Hartig W. Laser scanning and electron microscopic evidence for rapid and specific in vivo labelling of cholinergic neurons in the rat basal 
forebrain with fluorochromated antibodies. Brain Res 2000;867: 232-238.

39. Wu M, Shanabrough M, Leranth C, Alreja M. Cholinergic excitation of septohippocampal GABA but not cholinergic neurons: implications for learning and memory. J Neurosci 2000;20:39003908.

40. Alonso A, Khateb A, Fort P, Jones BE, Muhlethaler M. Differential oscillatory properties of cholinergic and noncholinergic nucleus basalis neurons in guinea pig brain slice. Eur J Neurosci 1996;8: 169-182.

41. Duque A, Balatoni B, Detari L, Zaborszky L. EEG correlation of the discharge properties of identified neurons in the basal forebrain. J Neurophysiol 2000;84:1627-1635.

42. Manns ID, Alonso A, Jones BE. Discharge properties of juxtacellularly labeled and immunohistochemically identified cholinergic basal forebrain neurons recorded in association with the electroencephalogram in anesthetized rats. J Neurosci 2000;20: 1505-1518.

43. Unal CT, Golowasch JP, Zaborszky L. Adult mouse basal forebrain harbors two distinct cholinergic populations defined by their electrophysiology. Front Behav Neurosci 2012;6:21.

44. O'Leary VB, Ovsepian SV, Bodeker M, Dolly JO. Improved lentiviral transduction of ALS motoneurons in vivo via dual targeting. Mol Pharm 2013;10:4195-4206.

45. Rosenberg MB, Hawrot E, Breakefield XO. Receptor binding activities of biotinylated derivatives of beta-nerve growth factor. $\mathrm{J}$ Neurochem 1986;46:641-648.

46. Holtzman DM, Kilbridge J, Li Y, et al. TrkA expression in the CNS: evidence for the existence of several novel NGF-responsive CNS neurons. J Neurosci 1995;15:1567-1576.

47. Lapchak PA, Araujo DM, Carswell S, Hefti F. Distribution of [125I]nerve growth factor in the rat brain following a single intraventricular injection: correlation with the topographical distribution of trkA messenger RNA-expressing cells. Neuroscience 1993;54: $445-460$.

48. Rossner S, Yu J, Pizzo D, et al. Effects of intraventricular transplantation of NGF-secreting cells on cholinergic basal forebrain neurons after partial immunolesion. J Neurosci Res 1996;45:40-56.

49. Lentz TB, Gray SJ, Samulski RJ. Viral vectors for gene delivery to the central nervous system. Neurobiol Dis 2012;48:179-188.

50. Maguire CA, Ramirez SH, Merkel SF, Sena-Esteves M, Breakefield XO. Gene therapy for the nervous system: challenges and new strategies. Neurotherapeutics 2014;11:817-839.

51. Anand P, Singh B. A review on cholinesterase inhibitors for Alzheimer's disease. Arch Pharm Res 2013;36:375-399.

52. Scatena R, Martorana GE, Bottoni P, Botta G, Pastore P, Giardina $\mathrm{B}$. An update on pharmacological approaches to neurodegenerative diseases. Expert Opin Investig Drugs 2007;16:59-72.

53. Tata AM, Velluto L, D'Angelo C, Reale M. Cholinergic system dysfunction and neurodegenerative diseases: cause or effect? CNS Neurol Disord Drug Targets 2014;13:1294-1303.

54. Ginsberg SD, Che S, Wuu J, Counts SE, Mufson EJ. Down regulation of Trk but not p75NTR gene expression in single cholinergic basal forebrain neurons mark the progression of Alzheimer's disease. J Neurochem 2006;97:475-487.
55. Iulita MF, Cuello AC. Nerve growth factor metabolic dysfunction in Alzheimer's disease and Down syndrome. Trends Pharmacol Sci 2014;35:338-348.

56. Mufson EJ, Counts SE, Perez SE, Ginsberg SD. Cholinergic system during the progression of Alzheimer's disease: therapeutic implications. Expert Rev Neurother 2008;8:1703-1718.

57. Apfel SC. Neurotrophic factor therapy-prospects and problems. Clin Chem Lab Med 2001;39:351-355.

58. Kay MA, Glorioso JC, Naldini L. Viral vectors for gene therapy: the art of turning infectious agents into vehicles of therapeutics. Nat Med 2001;7:33-40.

59. Alisky JM, Davidson BL. Gene therapy for amyotrophic lateral sclerosis and other motor neuron diseases. Hum Gene Ther 2000;11:2315-2329.

60. Brooks AI, Stein CS, Hughes SM, et al. Functional correction of established central nervous system deficits in an animal model of lysosomal storage disease with feline immunodeficiency virusbased vectors. Proc Natl Acad Sci U S A 2002;99:6216-6221.

61. Ghadge GD, Roos RP, Kang UJ, et al. CNS gene delivery by retrograde transport of recombinant replication-defective adenoviruses. Gene Ther 1995;2:132-137.

62. Ovsepian SV, Bodeker M, O'Leary VB, Lawrence GW, Oliver Dolly J. Internalization and retrograde axonal trafficking of tetanus toxin in motor neurons and trans-synaptic propagation at central synapses exceed those of its C-terminal-binding fragments. Brain Struct Funct 2015;220:1825-1838.

63. Deinhardt K, Salinas S, Verastegui C, et al. Rab5 and Rab7 control endocytic sorting along the axonal retrograde transport pathway. Neuron 2006;52:293-305.

64. Lalli G, Schiavo G. Analysis of retrograde transport in motor neurons reveals common endocytic carriers for tetanus toxin and neurotrophin receptor p75NTR. J Cell Biol 2002;156:233-239.

65. Ward NL, Stanford LE, Brown RE, Hagg T. Cholinergic medial septum neurons do not degenerate in aged $129 / \mathrm{Sv}$ control or p75(NGFR) $)^{-/}$mice. Neurobiol Aging 2000;21:125-134.

66. Lesch HP, Kaikkonen MU, Pikkarainen JT, Yla-Herttuala S. Avidin-biotin technology in targeted therapy. Expert Opin Drug Deliv 2010;7:551-564.

67. Livnah O, Bayer EA, Wilchek M, Sussman JL. Three-dimensional structures of avidin and the avidin-biotin complex. Proc Natl Acad Sci U S A 1993;90:5076-5080.

68. Pereboeva L, Komarova S, Roth J, Ponnazhagan S, Curiel DT. Targeting EGFR with metabolically biotinylated fiber-mosaic adenovirus. Gene Ther 2007;14:627-637.

69. Weber PC, Ohlendorf DH, Wendoloski JJ, Salemme FR. Structural origins of high-affinity biotin binding to streptavidin. Science 1989;243:85-88.

70. Lesch HP, Pikkarainen JT, Kaikkonen MU, et al. Avidin fusion protein-expressing lentiviral vector for targeted drug delivery. Hum Gene Ther 2009;20:871-882.

71. Morizono K, Xie Y, Helguera G, et al. A versatile targeting system with lentiviral vectors bearing the biotin-adaptor peptide. J Gene Med 2009;11:655-663.

72. Mufson EJ, Ma SY, Cochran EJ, et al. Loss of nucleus basalis neurons containing trkA immunoreactivity in individuals with mild cognitive impairment and early Alzheimer's disease. J Comp Neurol 2000;427:19-30. 